\title{
Anticancer property of Bryophyllum pinnata (Lam.) Oken. leaf on human cervical cancer cells
}

\author{
Sutapa Mahata ${ }^{1 \dagger}$, Saurabh Maru ${ }^{1 \dagger}$, Shirish Shukla ${ }^{1}$, Arvind Pandey ${ }^{1}$, G Mugesh² ${ }^{2}$ Bhudev C Das ${ }^{3^{*}}$ and \\ Alok C Bharti ${ }^{*}$
}

\begin{abstract}
Background: Bryophyllum pinnata (B. pinnata) is a common medicinal plant used in traditional medicine of India and of other countries for curing various infections, bowel diseases, healing wounds and other ailments. However, its anticancer properties are poorly defined. In view of broad spectrum therapeutic potential of B. pinnata we designed a study to examine anti-cancer and anti-Human Papillomavirus (HPV) activities in its leaf extracts and tried to isolate its active principle.

Methods: A chloroform extract derived from a bulk of botanically well-characterized pulverized B. pinnata leaves was separated using column chromatography with step- gradient of petroleum ether and ethyl acetate. Fractions were characterized for phyto-chemical compounds by TLC, HPTLC and NMR and Biological activity of the fractions were examined by MTT-based cell viability assay, Electrophoretic Mobility Shift Assay, Northern blotting and assay of apoptosis related proteins by immunoblotting in human cervical cancer cells.
\end{abstract}

Results: Results showed presence of growth inhibitory activity in the crude leaf extracts with $\mathrm{IC}_{50}$ at $552 \mu \mathrm{g} / \mathrm{ml}$ which resolved to fraction F4 (Petroleum Ether: Ethyl Acetate:: 50:50) and showed $I C_{50}$ at $91 \mu \mathrm{g} / \mathrm{ml}$. Investigations of anti-viral activity of the extract and its fraction revealed a specific anti-HPV activity on cervical cancer cells as evidenced by downregulation of constitutively active AP1 specific DNA binding activity and suppression of oncogenic c-Fos and cJun expression which was accompanied by inhibition of HPV18 transcription. In addition to inhibiting growth, fraction F4 strongly induced apoptosis as evidenced by an increased expression of the pro-apoptotic protein Bax, suppression of the anti-apoptotic molecules BCl-2, and activation of caspase-3 and cleavage of PARP-1. Phytochemical analysis of fraction F4 by HPTLC and NMR indicated presence of activity that resembled Bryophyllin A.

Conclusions: Our study therefore demonstrates presence of anticancer and anti-HPV an activity in B. pinnata leaves that can be further exploited as a potential anticancer, anti-HPV therapeutic for treatment of HPV infection and cervical cancer.

Keywords: Bryophyllum pinnata, Human Papillomavirus, HeLa cells, AP1, NMR, HPTLC

\section{Background}

For many centuries, plants have been a rich source of therapeutic agents and provided basis for several synthetic drugs. Despite great development of organic synthesis, currently $75 \%$ of prescribed drugs worldwide are derived from plant sources [1], showing that plant

\footnotetext{
* Correspondence: bcdas48@hotmail.com; bhartiac@icmr.org.in

+ Contributed equally

'Division of Molecular Oncology, Institute of Cytology and Preventive Oncology (ICMR), I-7, Sector-39, Noida 201301, INDIA

${ }^{3}$ Dr. B.R Ambedkar Centre for Biomedical Research, University of Delhi (North Campus), Delhi 110007, INDIA
}

Full list of author information is available at the end of the article species are still an important source of new drugs for diseases that continue to lack a cure, such as cancer.

Bryophyllum pinnatum (Lam.) (synonym: Kalanchoe pinnata, Lam.; common names: Life plant, air plant (Mexican), love plant, Canterbury bells, Cathedral bells, etc) is a perennial herb that grow in the wild and used as a traditional medicinal plant in tropical Africa, China, Australia, tropical America and Indian system of medicine- Ayurveda. The leaf extracts of this plant have been routinely used for ailments like bacterial, fungal and viral infections, asthma, kidney stones, and ulcers. The leaves of this plant have been reported to possess

\section{Biomed Central}


antimicrobial [2], antifungal [3], anti-ulcer [4], antiinflammatory and analgesic [5,6], antihypertensive [7], antidiabetic [8] and antimutagenic activities [9]. A number of active compounds, including flavonoids, glycosides, steroids, bufadienolides and organic acids have been identified in B. pinnata [10-12] that have been shown individually to possess variety of activities such as antibacterial, antitumor, cancer preventive and insecticidal actions. The flavonoid glycoside, Quercitrin (quercetin 3- O- alpha- L-rhamnopyranoside) and skap innato side were isolated with anti-leishmanial activity [13-17]. Despite having broad spectrum therapeutic potential, B. pinnata's anticancer activity in general and anti-HPV activity in particular have not been explored as yet.

Cervical cancer is the principal cause of cancer-related mortality in women of the developing countries that contribute more than $85 \%$ of global disease burden [18]. Persistent infection with high-risk human papillomavirus (HR-HPV), most notably of the type 16 and 18 , is an essential prerequisite for the development of cervical cancer [19-23] resulting in dysregulation of host cell cycle by targeting pivotal cell cycle proteins $\mathrm{p} 53$ \& $\mathrm{pRb}$ by their viral gene products E6 \& E7, respectively. Constitutive expression of HR-HPV E6 and E7 oncogene is mainly dependent on the availability of host cell transcription factors that act upon viral promoter and enhancer region. Activator protein-1 (AP1), a heterodimer of a group of structurally and functionally related members of the Jun (c-Jun, JunB, JunD) and Fos family (c-Fos, FosB, Fra-1 and Fra-2) is one of the transcription factors that are essentially required for viral oncogene expression [24]. Mutational inactivation of AP1 cis-acting site within the HR-HPV upstream regulatory region (URR) that facilitates AP1 interactions revealed a complete loss of transcriptional activity of the E6/E7 promoter and showed a key role of AP1 in HPV-mediated carcinogenesis [25]. Studies by our group demonstrated a significant overexpression of constitutively active AP1 family members in cervical precancer and cancer tissues [26]. Though HPV-mediated mechanism of cervical carcinogenesis is now well defined, anti-HPV therapeutics for elimination of HPV infections are yet to become a clinical reality and conventional physical ablation of $\mathrm{HPV}$ - infected lesions in precancer stage are in clinical practice [27]. Currently, there is no HPV specific advanced therapy for treatment of cervical cancer. Recent studies have shown that anti-oxidants and herbal derivatives may be effective against prevailing HR-HPV infection but these leads are yet to prove their efficacy in preclinical and subsequent clinical studies [26-29].

In view of absence of anti-HPV therapeutic for prevention and treatment of cervical cancer, in the present study, we examined leaves of B. pinnata for presence of anti-cancer and anti-HPV activity against human cervical cancer cells, HeLa that harbors HR-HPV type 18.

\section{Materials and methods \\ Materials}

The HPV18 positive human cervical cancer cell line, HeLa was obtained from the American Type Culture Collection (ATCC), USA. Polyclonal antibodies to Caspase-3, PARP-1, Bax, Bcl-2, $\beta$-actin, c-Jun, JunB, JunD, and c-Fos were purchased from Santa Cruz Biotechnology (Santa Cruz, CA). Dulbecco's modified Eagle's medium (DMEM), Fetal calf serum (FCS), 3-(4, 5dimethylthiazol-2-yl) -2, 5-diphenyltetrazolium bromide (MTT), penicillin-streptomycin solution and all other reagents used in present study were of analytical grade and purchased from Sigma (St Louis, MO).

\section{Collection of plant material and identification}

The leaves of $B$. pinnata were collected from Indore region of Madhya Pradesh (MP), India in the month of March-April, identified and authenticated by the Department of Botany, Devi Ahilya Vishwavidyalaya, Indore, Madhya Pradesh, India. The collected plant material was made free from foreign organic matter.

\section{Extraction and separation through column chromatography}

Fresh leaves $(20 \mathrm{~kg})$ were crushed, washed with water and filtered. After filtration, the residual leaf material was dried and extracted with chloroform (Soxhlet extraction). The chloroform extract then dried and designated A. On the other hand, the filtered water was shaken with chloroform. The chloroform layer then separated from water layer, dried and designated $B$. Finally, both the extract $\mathrm{A}$ and $\mathrm{B}$ were mixed together and designated $C$ (26.44 gm). The $C$ was separated through silica gel column chromatography with the solvent petroleum ether (100-0\%) to ethyl acetate (0-100\%) in gradient step and final elution was performed with $100 \%$ methanol. Thus resulting in 6 different fractions that were designated from Fraction F1 to Fraction F6 (Figure 1). Finally fractions were concentrated under vacuum.

\section{Thin layer chromatographic (TLC) analysis}

All the fractions were applied on to the precoated silica gel TLC plates and chromatographed using the solvent system chloroform: methanol (95:5). Plates were examined under UV and visible light as described earlier.

\section{Phytochemical analysis}

Specimen from each fraction was examined to check the presence of bioactive phytochemicals using different chemical tests. Raymond test was performed for 


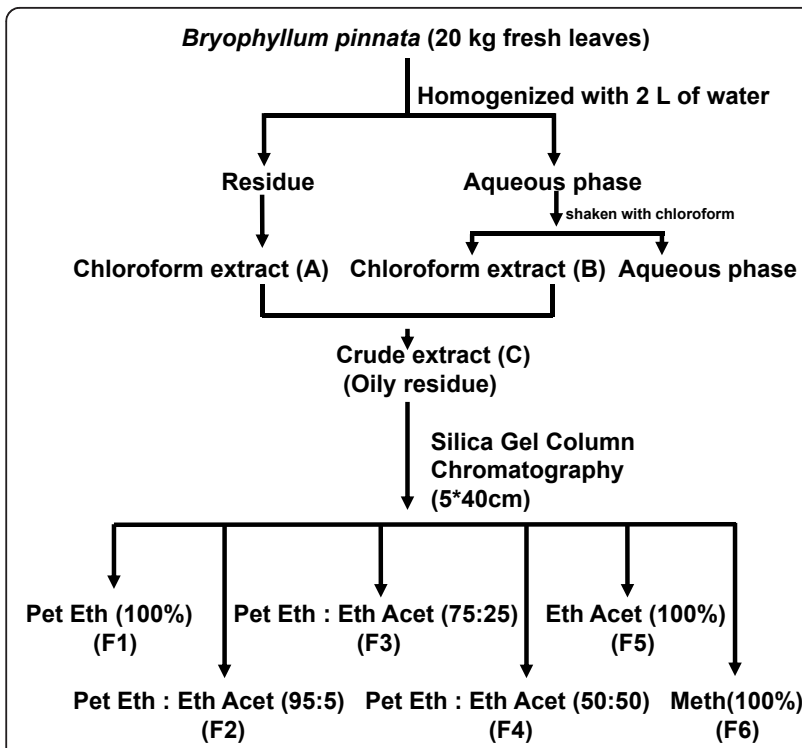

Figure 1 Flow chart of extraction and column chromatographic separation of Bryophyllum pinnata leaves. $20 \mathrm{~kg}$ fresh leaves of $B$. pinnata were crushed with water and filtered. Residue was dried and extracted with chloroform and fractionated with gradient of petroleum ether and ethyl acetated followed by washing with methanol. Fractions were designated as F1 to F6 as indicated in the figure. Pet Eth, Petroleum Ether; Eth Acet, Ethyl Acetate; Meth, Methanol.

detecting the presence of steroidal glycosides. Briefly, 0.5 $\mathrm{g}$ of the extracts was dissolved in $1 \mathrm{ml}$ of $50 \%$ ethanol and $0.1 \mathrm{ml} 1 \%$ solution of metadinitrobenzene in methanol. 2-3 drops of $20 \%$ sodium hydroxide were added that lead to violet coloration which changed to blue with presence of steroidal glycosides. Dragendorff's test was performed for detecting the presence of alkaloids. Briefly, $0.5 \mathrm{~g}$ of dried extracts was dissolved in methanol and added with Dragendorff's reagent. Turbidity and precipitation indicated the positive test for alkaloids.

Nuclear Magnetic Resonance (NMR) spectroscopy analysis Specimens from each fraction were subjected to Proton NMR (Bruker AMX-400 NMR spectrometer). $\left({ }^{1} \mathrm{H}\right.$ NMR) spectra were recorded in $\mathrm{CDCl} 3$ on $400 \mathrm{MHz}$. Chemical shifts are cited in ppm with respect to SiMe4 as an internal control.

\section{High Performance Thin Layer Chromatographic (HPTLC) analysis}

Silica gel $60 \mathrm{~F}_{254}(10 \mathrm{~cm} \times 10 \mathrm{~cm} ; 2 \mathrm{~mm}$ thickness, E. Merck, Darmstad, Germany) was used as stationary phase and extract band (application volume $8 \mu \mathrm{l}$, width $8 \mathrm{~mm}$, space between bands $14 \mathrm{~mm}$ ) was applied on the plate with CAMAG Micro-liter syringe. Chloroform: methanol (9.5:0.5 v/v) was used as mobile phase. Chamber was saturated for $15 \mathrm{~min}$ at room temperature. The length of chromatogram run was $85 \mathrm{~mm}$. Plate was developed for $90 \mathrm{~min}$ in Twin trough glass chamber (CAMAG, Muttenz, Switzerland). Densitometric analysis was done with CAMAG TLC scanner III with scanning speed of $20 \mathrm{~mm} / \mathrm{sec}$ at detection wave length of $360 \mathrm{~nm}$ and $615 \mathrm{~nm}$ by employing D2 \& W lamp as radiation source and the procedure were operated by winCATS software (Ver. 1.2.0). Chromatogram recorded on two modes, first before and then after spraying anisaldehydesulphuric acid (AS) reagent. CAMAG Linomat-V application (CAMAG, Muttenz, Switzerland) was used for all above analysis.

\section{Cell culture}

HeLa cells were cultured in DMEM supplemented with $10 \%$ FCS, $100 \mathrm{U} / \mathrm{ml}$ penicillin, $100 \mu \mathrm{g} / \mathrm{ml}$ streptomycin and maintained at $37^{\circ} \mathrm{C}$ in a humidified atmosphere of $5 \% \mathrm{CO}_{2}$ as recommended by ATCC. B. pinnata was freshly dissolved in DMSO prior to cell culture treatment and cells were treated with variable concentration of B. pinnata crude extract and its fractions (F1-F6) and examined for viability, AP-1 DNA binding activity and other molecular assays as described.

\section{MTT assay}

The cells $\left(1 \times 10^{3}\right)$ seeded in 96-well plate and grown overnight, were treated with crude extract and different fractions at indicated concentration for $24 \mathrm{~h}, 48 \mathrm{~h}$ and $72 \mathrm{~h}$. Two hours prior to completion of treatment duration, cultures were supplemented with MTT. After the incubation at $37^{\circ} \mathrm{C}$, the cells were lysed with lysis buffer containing $50 \%$ of dimethyl formamide and 20\% SDS and absorbance was measured at $570 \mathrm{~nm}$ using microtitre plate reader (Biotek, Winooski, Vermont) as described earlier [28]. The percentage of cell viability was calculated using the following formula: Percentage cell viability $=(\mathrm{OD}$ of the experiment samples $/ O D$ of the control) $\times 100 . \mathrm{IC}_{50}$ was calculated by linear interpolation method using the formula: $\mathrm{IC}_{50}=[(50-\mathrm{A}) /(\mathrm{B}-$ $A)] \times(D-C)+C$, where $A=$ the first point on the curve, expressed in percent inhibition, that is less than $50 \%$; $\mathrm{B}=$ the first point on the curve, expressed in percent inhibition, that is greater than or equal to $50 \%$; $\mathrm{C}=$ the concentration of inhibitor that gives $\mathrm{A} \%$ inhibition; and $\mathrm{D}=$ the concentration of inhibitor that gives $\mathrm{B} \%$ inhibition [30].

\section{Isolation of Nuclear Proteins and Electrophoretic mobility} shift assay (EMSA)

Nuclear proteins were isolated from treated and control HeLa cells and were subjected to EMSA to assess AP1 -specific DNA binding as previously described [28]. Briefly, cells treated with different concentration of crude extract and fraction F4 for 24 hours were 
harvested and then nuclear extracts were prepared. The protein concentration of the extracts was measured by the spectrophotometric method using Nanodrop spectrophotometer (ND-1000). For EMSA, $10 \mu \mathrm{g}$ of nuclear proteins from each sample were incubate with ${ }^{32} \mathrm{P}$ radio labeled oligonucleotide probe containing consensus sequence 5'-CGCTTGATGACTCAGCCGGAA-3' that binds AP1 proteins. The DNA-protein complexes were then resolved on $4.5 \%$ non-denaturing PAGE, dried and exposed overnight to Kodak X-Omat Films (Kodak India Ltd., India). The quantitative densitometric analysis was performed using Alpha Ease FC version 4.1.0 (Alpha Innotech Corporation, IL). Binding specificity of AP1 probe was checked by using nuclear proteins of HeLa cells with unlabelled 100x molar excess of cold specific competitor (AP1) and non-specific competitor (Oct-1; 5'-TGTCGAATGCAAATCACTAGAA- 3').

\section{Isolation of whole cell protein and immunoblotting}

Whole-cell proteins were isolated as described earlier [28] and protein concentration was determined using Nanodrop spectrophotometer (ND-1000). For immunoblotting, $50 \mu \mathrm{g} / \mathrm{ml}$ of cellular protein/lane was separated on 10\% SDS-PAGE and electrotransferred to ImmobilinP membranes (Millipore Corporation, Bedford, MA). Blots were blocked with $5 \%$ non-fat milk in PBS containing $0.05 \%$ Tween (PBST), rinsed in PBST and incubated overnight at $4{ }^{\circ} \mathrm{C}$ with the indicated primary antibodies in PBST containing 5\% milk. Blots were again washed in PBST and further incubated with HRPconjugated secondary antibody (Santa Cruz Biotech USA). The bands were visualized using the Luminol reagent detection kit (Santa Cruz Biotech, USA) and exposed to autoradiography film (Kodak). The western blot membranes were re-probed for $\beta$ - actin expression as an internal control. The quantitative densitometric analysis of the bands was performed using Alpha Ease FC version 4.1.0 (Alpha Innotech Corporation, IL). The expression level of proteins was quantitated with respect to $\beta$-actin.

\section{RNA isolation and northern blotting}

The total cellular RNA was extracted from treated and control HeLa cells using TRI reagent (Sigma- Aldrich, USA) according to the manufacturer's instruction. The quality of RNA was estimated by electrophoresis using 2 $\mu \mathrm{l}$ of RNA solution on an ethidium bromide-stained 1\% agarose gel in 3-[N- morpholino] propane-sulfonic acid (MOPS) buffer. Concentration of RNA was estimated spectrophotometrically by Nanodrop (NanoDrop Tech, USA). The probes were labeled by the random-priming method using random primer labelling kit (Genei, Bangalore, India) and northern blotting was carried out. Briefly, approximately $15 \mu \mathrm{g}$ of RNA was resolved on
$1 \%$ agarose- MOPS formaldehyde gel. Capillary blotted Nylon membrane (IMMOBILON-NY+, Millipore, Bedford, MA) was then UV crosslinked (Hoefer UVC 500 ultraviolet crosslinker, Amersham Biosciences, England) and washed in 6X SSC, air dried, and finally exposed in phosphorimager (Fujifilm FLA-5100, Japan) after prehybridization and hybridization in Perfect HYB-PLUS (Sigma Inc, USA) solution as suggested by manufacturer's protocol.

\section{Results}

Column chromatographic separation, thin layer chromatography and phytochemical analysis of $B$. pinnata leaf extract

Chromatographic separation of $B$. pinnata leaf extracts was performed that produced a total of 6 fractions (Figure 1). Sample from each fraction was spotted on precoated silica gel thin layer chromatographic plate and eluted with chloroform: methanol (95:5) solvent system. TLC plates were observed under visible and UV light. Results showed presence of UV active spots in crude extract, and fraction F1, F3 and F4 (data not shown). The spots with UV activity were found with very low Rf value. The phytochemical analysis of chromatographically separated fractions by Raymond's test for cardiac glycosides and Dragendorff's test for alkaloids were performed that showed presence of alkaloids and steroidal glycosides only in fraction F3 and F4 (Table 1). The F4 was observed to be rich in steroidal glycosides, alkaloids and steroids and F3 gave only a faint coloration in both the reactions. All the other fractions failed to show presence of any of these bioactive compounds.

\section{Comparative analysis of $B$. pinnata and its fractions for growth inhibitory activity against cervical cancer cells} B. pinnata crude leaf extract and all its chromatographic fractions were examined for cell-growth inhibitory properties on HeLa cells. Cells treated with indicated concentration of test sample were examined by MTT assay for the cell viability. Results shown in Figure 2A demonstrate presence of growth inhibitory property in crude extract and its fraction F4 whereas fraction F3 had minor growth promoting activity. Crude B. pinnata leaf extract inhibited

Table 1 Analysis of various chromatographic fraction of B.pinnata leaf extract for presence of bioactive phytochemicals

\begin{tabular}{|c|c|c|c|c|c|c|c|}
\hline \multirow[t]{2}{*}{ S. N. } & \multirow[t]{2}{*}{ Test } & \multicolumn{6}{|c|}{$\begin{array}{l}\text { Colorimetric/ } \\
\text { turbidity test }\end{array}$} \\
\hline & & F1 & F2 & F3 & F4 & F5 & F6 \\
\hline 1 & Raymond test (Cardiac Glycosides) & - & - & + & ++ & - & - \\
\hline 2 & Dragendorff's test (Alkaloids) & - & - & + & ++ & - & - \\
\hline
\end{tabular}

+ - Normal coloration; ++ - Dense coloration, -No change, F1 to F6 designated chromatographic fraction of $B$. pinnata leaf extract. 


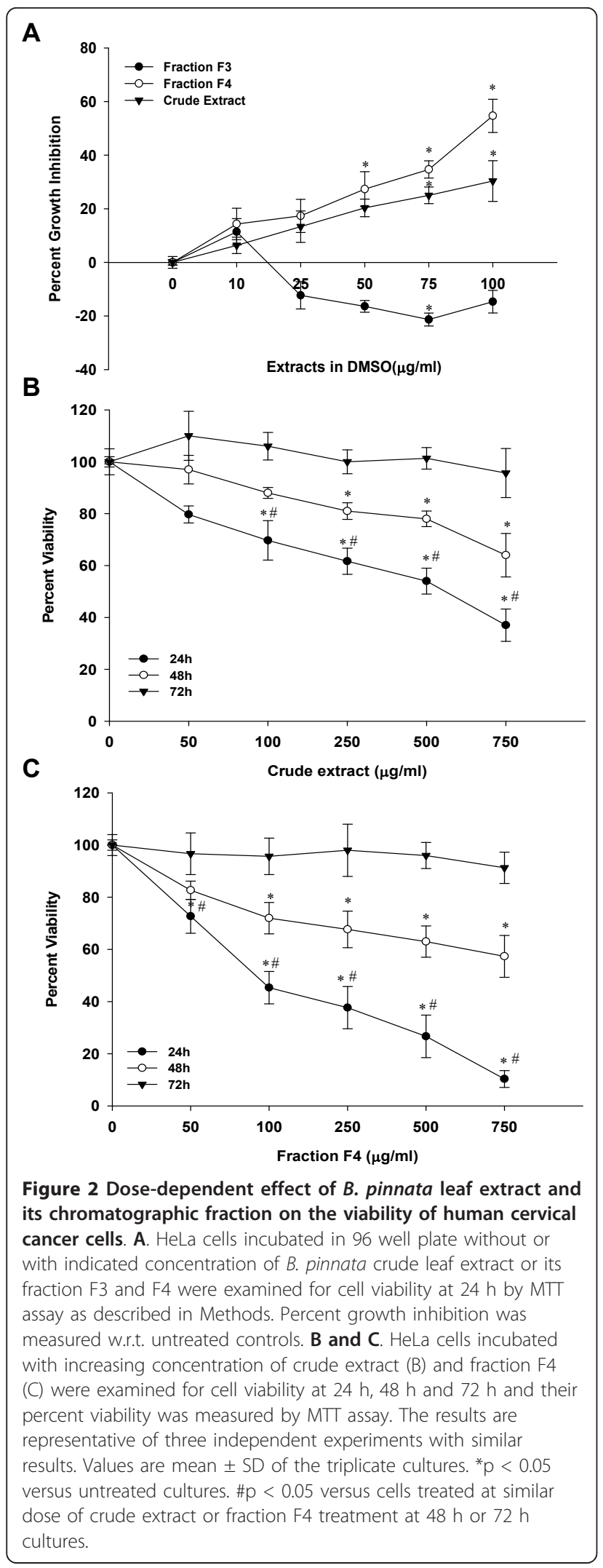

cervical cancer cell growth by $30 \%$ whereas fraction F4 was comparatively more potent and inhibited cell growth by $55 \%$ at $100 \mu \mathrm{g} / \mathrm{ml}$ concentration (Figure $2 \mathrm{~A}$ ). On the other hand, growth of cells treated with fraction F3 was found to be relatively higher compared to control which was maximum $(-21.3 \%)$ at $75 \mu \mathrm{g} / \mathrm{ml}$. Further increase in F3 concentration did not increase the growth of cervical cancer cells. Cells treated with other fractions did not show any significant change in their growth properties (data not shown). Based on these preliminary observations, cells were treated with increasing concentration of crude extracts and fraction F4 for $24 \mathrm{~h}, 48 \mathrm{~h}$ and $72 \mathrm{~h}$ to examine the dose kinetics and time course of growth inhibition. As shown in Figure 2B and 2C, both the crude extract and fraction F4 showed highest dose-dependent inhibition at $24 \mathrm{~h}$. A longer incubation of treated cultures resulted in partial recovery of growth inhibition at $48 \mathrm{~h}$ and complete recovery by $72 \mathrm{~h}$. The interpolated IC50 of crude extract was $552 \mu \mathrm{g} / \mathrm{ml}$ and IC50 of fraction F4 was $91 \mu \mathrm{g} / \mathrm{ml}$ in $24 \mathrm{~h}$ treated cultures.

\section{B. pinnata suppress constitutive activation of AP1 in cervical cancer cells}

To assess anti-HPV activity of $B$. pinnata extracts, we next examined the effect of crude extracts and fraction F4 on activity and expression of transcription factor AP1. Nuclear proteins isolated from HeLa cells treated with increasing concentration of B. pinnata crude extract and fraction F4 were subjected to EMSA to assess AP1's DNA binding activity. Result in Figure 3A show high levels of constitutively active AP1 in untreated control cells which decreased dose-dependently in cells treated with both $B$. pinnata crude extracts and fraction F4. However, the crude extracts were found to be more effective in abrogating the constitutive activity of AP1 (Figure 3Aa and 3Ab). The specificity of AP1 binding was found to be specific as nuclear extracts of untreated HeLa cells co-incubated with cold competitor, unlabelled AP1 probe, completely quenched the AP1 specific binding to the labeled probe (Figure 3Ac), whereas it remained unaffected in the presence of a heterologous Oct-1 probe. Since loss of AP1 activity could be a direct result of loss of expression of AP1 family protein that forms functional homo/heterodimer of active AP1 complex, we checked the effect of B. pinnata crude leaf extract and fraction $\mathrm{F} 4$ on expression of AP1 family proteins, c-Jun, JunB, JunD and cfos in the treated cells by immunoblotting. Results shown in Figure 3B demonstrate a specific inhibitory

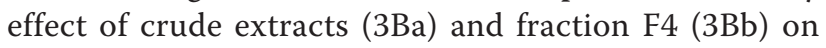
c-Jun and c-Fos whereas treatment of HeLa cells either by crude extract or fraction F4 did not alter expression 


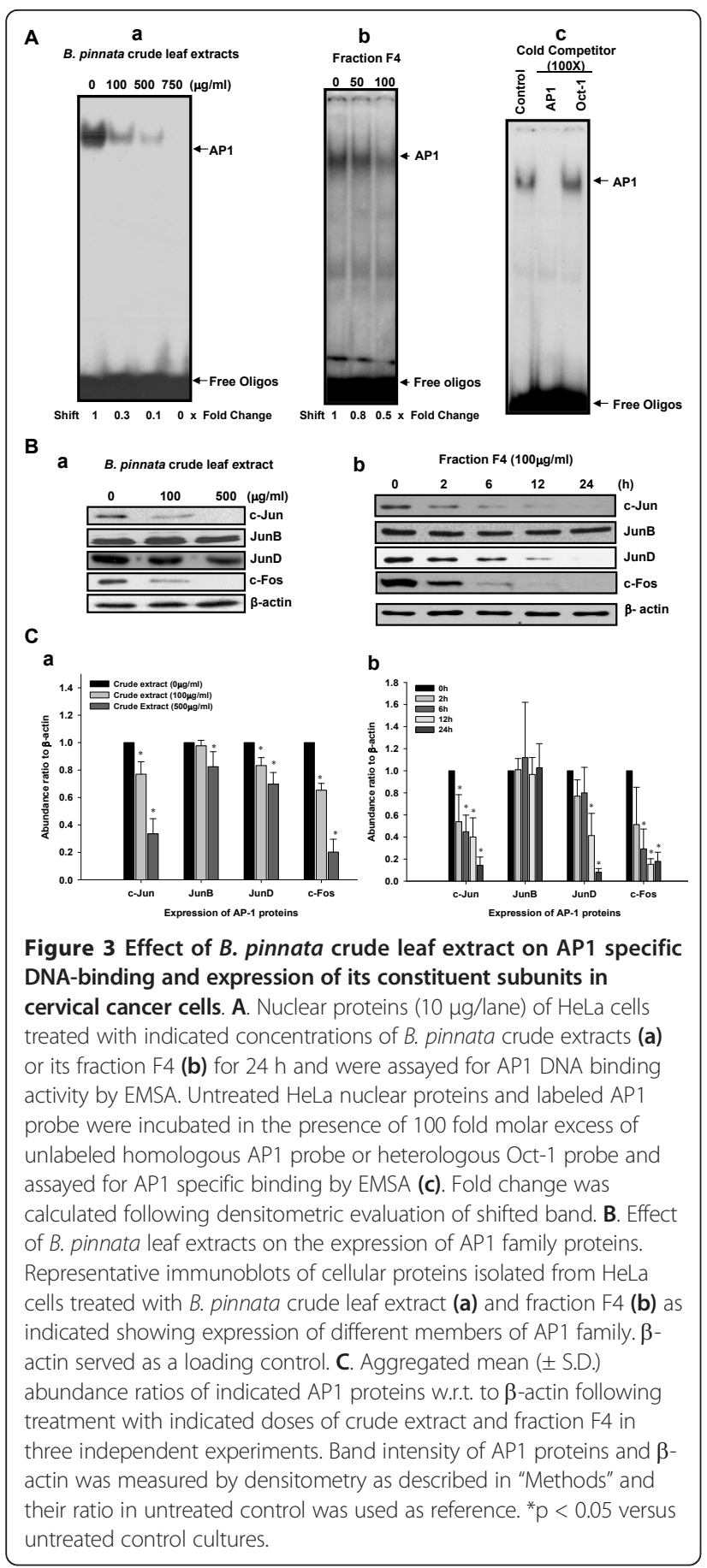

of JunB. Interestingly, fraction F4-treated cells showed specific inhibition of JunD which was not significantly altered in cells treated with crude extracts.

\section{Anti-HPV and pro-apoptotic activity of $B$. pinnata fraction} F4 in cervical cancer cells

As crude extract and fraction F4 inhibited pivotal host transcription factor AP1 in cervical cancer cells, in the next part of the investigation, we examined effect of $B$. pinnata crude extract and fraction F4 on transcription of viral mRNA transcripts by Northern blotting using HPV18-specific, radiolabelled probe. Results shown in Figure 4A depict a dose-dependent decrease in the level of HPV18 transcripts in cells treated with crude extracts and fraction F4. Interestingly, despite having lesser cytotoxic activity crude extract was found to be more potent in suppressing HPV18 expression as compared to fraction F4 (Figure 4Ba and $4 \mathrm{Bb}$ ). As cell toxicity could be outcome of either apoptotic or necrotic death that represents specific phytochemicals-induced programmed cell death or non-specific cell killing respectively, we examined the cells treated with $B$. pinnata fraction $\mathrm{F} 4$ for expression of apoptosis-associated proteins like Bax, Bcl-2, Caspase- 3 and PARP-1 by immunoblot analysis. Results in Figure 4C demonstrate appearance of fraction F4- induced a gradual increase in expression of proapoptotic Bax and elimination of anti-apoptotic protein Bcl-2 with in $12 \mathrm{~h}$. The changes in Bcl-2 and Bax expression were accompanied by cleavage of procaspase3 and PARP-1 that represent hallmark features of cells undergoing apoptotic cell death. Caspase-3 activation and cleavage of PARP-1 were found to be late event as they appeared by $24 \mathrm{~h}$ and proceeded the alteration in Bax/Bcl-2 levels (Figure 4D).

\section{Nuclear magnetic resonance and High performance thin layer chromatographic analysis of fraction F4}

In an effort to characterize the active principle, fraction F4 was examined by NMR spectroscopy and compared with other UV active fractions, F1 and F3 that served as controls. As shown in Figure 5, NMR spectra of B. pinnata leaf extract, fraction F4 was rich in magnitude and number of functional groups present on constituent chemical entities. The NMR spectra of fraction F4 was matched with the reported data which showed presence of specific peaks of functional groups like $\delta 5.13,4.36$, 1.42 (orthoacetate), $\delta 10.31$ (an aldehyde), $\delta 7.22$, and 6.27 ( $\alpha$-pyrone), $\delta 4.21$ (secondary hydroxyl) but at very low intensity indicating a possibility of presence of low concentration of bryophyllin A. Fraction F4 was further subjected to HPTLC analysis to determine relative ratio of different compounds within this fraction and compared it with fraction F3 to classify the compounds that are unique to F4 only. To analyze and detect compounds with UV activity and terpenoidal structure the HPTLC chromatograms of these fractions were analyzed in two modes, one, without spraying any reagent and visualized at $366 \mathrm{~nm}$ wavelength light and second, spraying anisaldehyde sulphuric (AS) reagent and visualized at $615 \mathrm{~nm}$ wavelength light. The HPTLC profiles shown in Figure 6 demonstrate presence of 11 substances before and after spraying AS reagent in fraction 


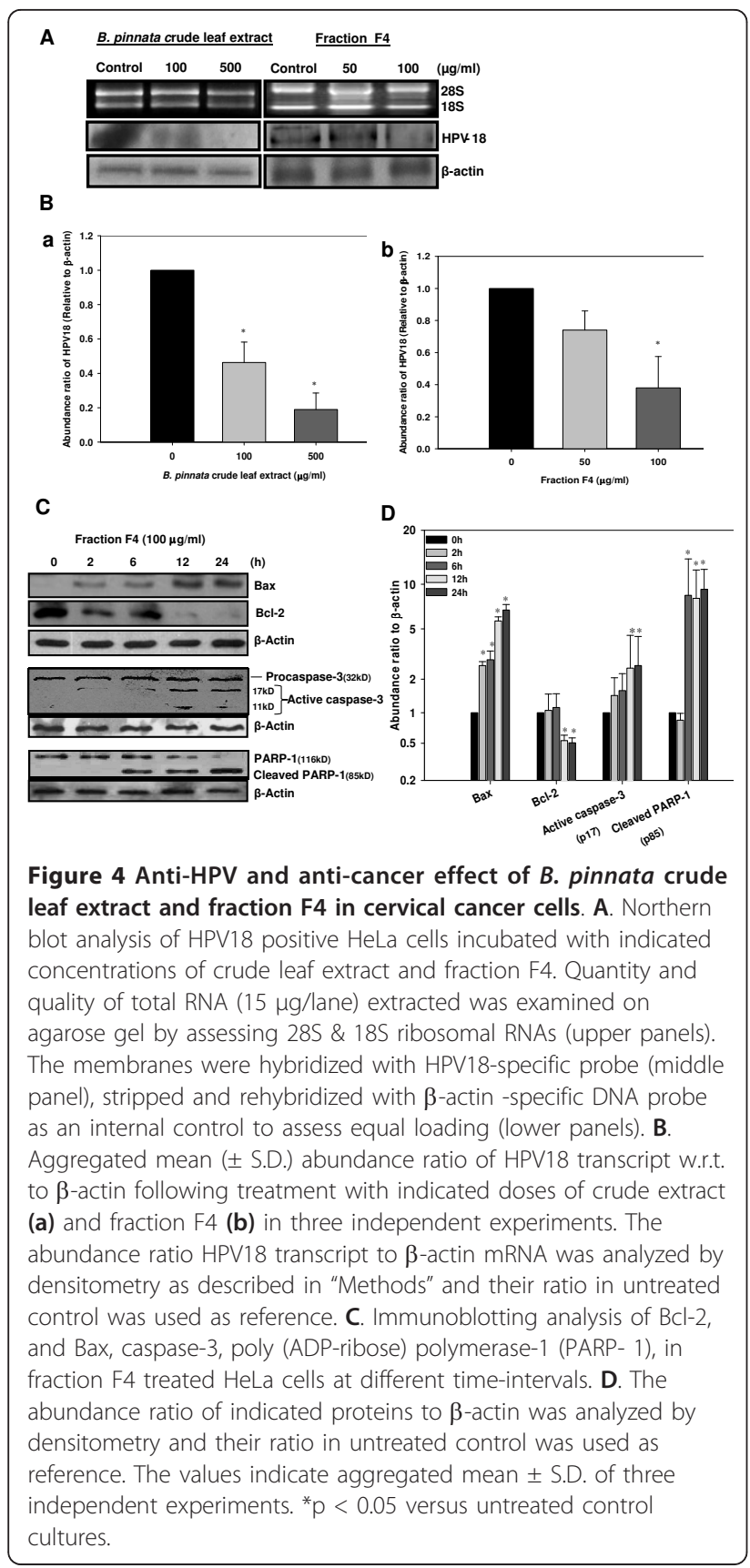

F3, and 8 \& 9 substances in fraction F4 before and after spraying AS reagent, respectively. Constituent substances were designated with numbers accordingly to their order of relative abundance. As summarized in Table 2 before spraying AS reagent there were 5 (substance \# 2, $\mathrm{R}_{\mathrm{f}} 0.91$; substance \# $8, \mathrm{R}_{\mathrm{f}} 0.03$; substance \# $18, R_{\mathrm{f}} 0.06$; substance \# $11, \mathrm{R}_{\mathrm{f}} 0.23$; \& substance \# $12, \mathrm{R}_{\mathrm{f}}$ 0.14 ) and 2 (substance \# $9, R_{f} 0.12$ \& substance \# $13, R_{f}$ $0.20)$ substances that were detectable were uniquely present in fraction F3 and F4 respectively that visualized at $366 \mathrm{~nm}$. Whereas after spraying the AS reagent, 4

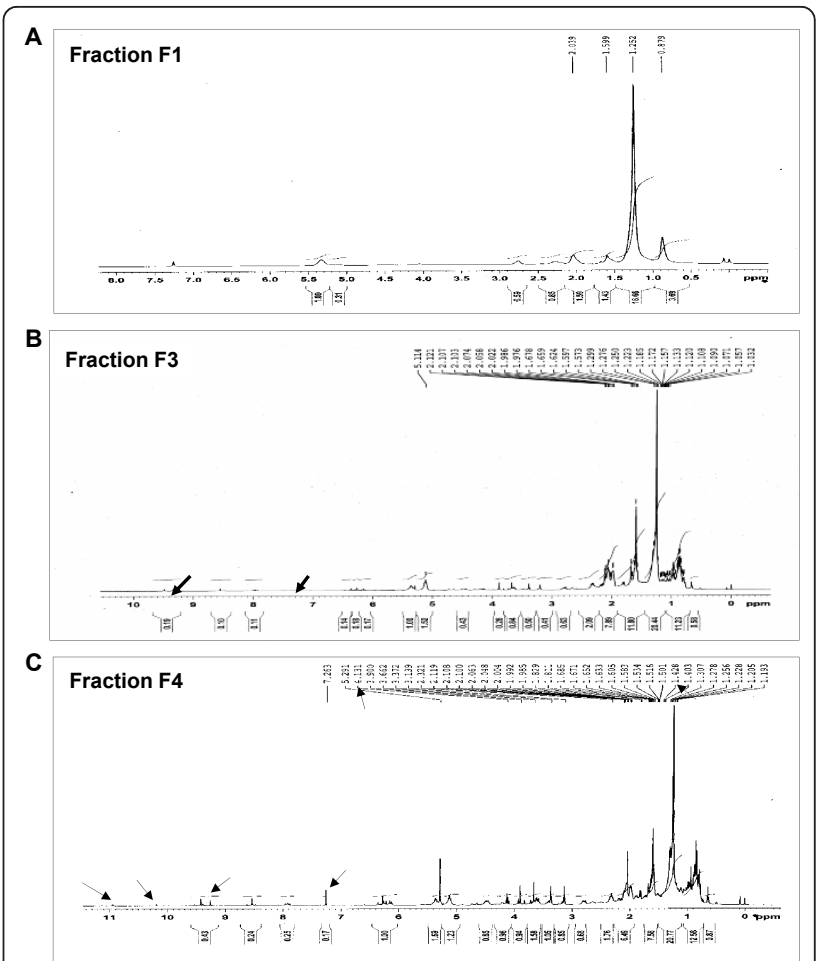

Figure 5 Functional group analysis of UV active B. pinnata fractions by Proton NMR. Fraction F1, F3 and F4 were dissolved in $\mathrm{CDCl} 3$ and NMR was taken at $400 \mathrm{MHz}$.

(substance \# 2, $\mathrm{R}_{\mathrm{f}} 0.63$; substance \# 9, $\mathrm{R}_{\mathrm{f}} 0.15$; substance \# 10, $\mathrm{R}_{\mathrm{f}} 0.56$; \& substance \# 13, $\mathrm{R}_{\mathrm{f}} 0.25$ ) and 2 (substance \# $7, R_{\mathrm{f}} 0.81$; \& substance \# $11, \mathrm{R}_{\mathrm{f}} 0.51$ ) substances were uniquely present in fraction F3 and F4 respectively when visualized at $615 \mathrm{~nm}$.

\section{Discussion}

In the present study, we extracted, purified and partially characterized an anti-cancer and anti-HPV molecule/ compound from leaves of B. pinnata of Indian origin. Using human cervical cancer cells in vitro examination of B. pinnata crude extracts and its specific chromatographic fractions revealed presence of a growth inhibitory activity that resolved to fraction F4. Further analysis of molecular events revealed a dose-dependent inhibition of constitutively active AP1 by abrogating its DNA-binding activity and expression of AP1 family proteins specifically c-Jun and c-Fos, two components of canonical functional forms of AP1. B. pinnata leaf extract suppressed viral transcription of HPV18 in these cervical cells in conjunction with inhibition of AP1 and caused apoptotic cell death as revealed by appearance of Bax, loss of Bcl-2 and cleavage of procaspase- 3 to active caspase- 3 and proteolytic loss of its target PARP-1. NMR and HPTLC analysis of fraction F4 indicated presence of alkaloids and steroidal glycosides one of which 


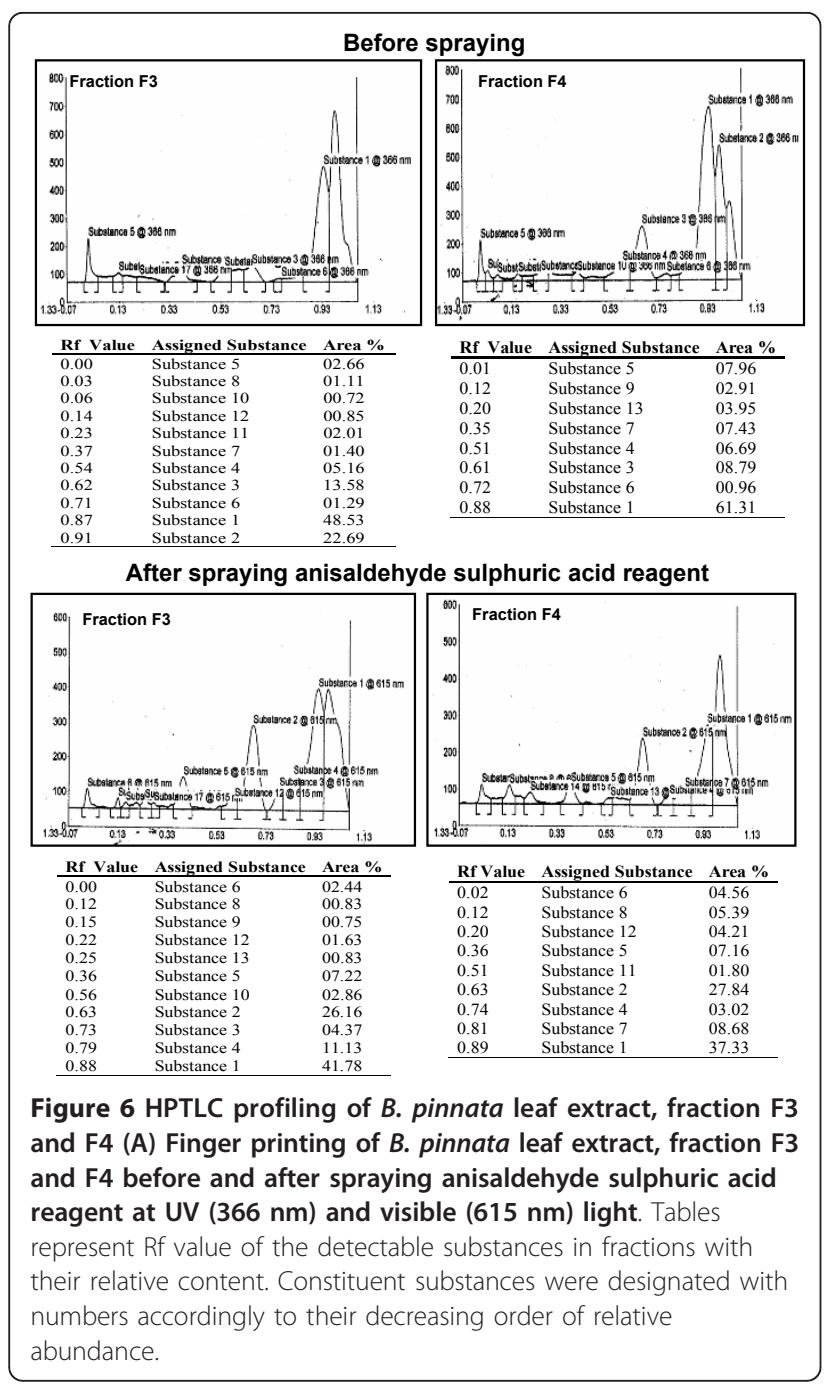

could be bryophyllin A. The chloroform-based extraction procedure used in the present study has been routinely followed by several other studies exploring therapeutic phytochemical [31]. The procedure focused primarily on the chloroform-extracted fraction only and the activity, if any, in the aqueous phase was intentially left out as the same could be potentially contaminating for cell culture as they are likely to possess bacteria and fungal spores and hence could have interfered with the assay. However earlier studies show presence of cytotoxic activities such as bryophyllin B that converges in aqueous phase [31] and could prove useful. Therefore, more refined extraction method are needed to resolve the anti-cancer activity by examining the extract without separation with chloroform as demonstrated by some of the investigators [32] and will be considered in future studies.

A dose-dependent cytotoxic activity observed in leaf extract and its fraction F4 demonstrates a potential therapeutic utility of this medicinal plant against cervical cancer. Earlier studies by Yamagishi et al. 1989 demonstrated presence of similar cytotoxic activity against KB cells in methanolic extracts of B. pinnata [31]. Additionally, antitumor activity of $B$. pinnata leaves owing to its antimutagenic activity has also been demonstrated [32]. Interestingly, comparative analysis of fractionated crude leaf extracts in our experiments revealed cytotoxic activity that specifically resolved in pet ether: eth acet::50:50. Earlier studies also show that antimutagenic activity can be extracted in pet ether and ethyl acetate [32]. However, the $\mathrm{IC}_{50}$ value derived from HPLC purified active principles from chloroform extracted $B$. pinnata plant in earlier studies [31] were much lower (ranged between $10 \eta \mathrm{g} / \mathrm{ml}-4 \mu \mathrm{g} / \mathrm{ml}$ ) compared to the one isolated in current study $(91 \mu \mathrm{g} / \mathrm{ml})$. This may be partly due to incomplete separation, but the variability of sensitivity of the cell line used in present study, could also be a major contributor. As a general notion, HeLa cells are much more resistant than many cell lines. Therefore, further studies are warranted on a panel of cell lines to verify the anti-cancer potential of fraction F4. Moreover, the inhibitory effect of both crude extract and fraction F4 were maximal at $24 \mathrm{~h}$ but declined thereafter. These observations suggest that active principle might get metabolized or get inactivated during culture process and is no more available to impose growth inhibitory

Table 2 Analysis for presence of unique substances in fraction F3 and F4 before and after spraying anisaldehyde sulphuric acid reagent

\begin{tabular}{|c|c|c|c|c|c|c|c|c|}
\hline \multirow[b]{2}{*}{ S.N } & \multicolumn{3}{|c|}{ Before Spraying } & \multicolumn{5}{|c|}{ After Spraying Anisaldehyde Sulphuric Acid Reagent } \\
\hline & Substance & Rf value & F3 & F4 & Substance & Rf value & F3 & F4 \\
\hline 1 & Substance 2 & 0.91 & + & - & Substance 2 & 0.63 & + & - \\
\hline 2 & Substance 8 & 0.03 & + & - & Substance 7 & 0.81 & - & + \\
\hline 3 & Substance 9 & 0.12 & - & + & Substance 9 & 0.15 & + & - \\
\hline 4 & Substance 10 & 0.06 & + & - & Substance 10 & 0.56 & + & - \\
\hline 5 & Substance 11 & 0.23 & + & - & Substance 11 & 0.51 & - & + \\
\hline 6 & Substance 12 & 0.14 & + & - & Substance 13 & 0.25 & + & - \\
\hline 7 & Substance 13 & 0.20 & - & + & - & & - & - \\
\hline
\end{tabular}


effect. However, these assumptions need further investigation.

In contrast to fraction F4, fraction F3 showed a minor growth promoting activity in dose range $50-100 \mu \mathrm{g} / \mathrm{ml}$. These results, suggest accumulation of cell growth promoters in F3 fraction that may have coexisted in the plant leaves along with cytotoxic activity. However, there is no report which specifically describes any tumor growth promoting activity associated with this plant.

Our results indicated that $B$. pinnata leaf extracts and its fraction F4 specifically inhibited URR-directed gene expression of HPV18. Constitutively active AP1 by itself has oncogenic outcome because of its regulatory role in several cellular processes like inflammation [33]. Moreover, AP1 is also essentially required for the maintenance of HPV expression through cis-acting binding sites on URR of HPV18. In contrast to higher cytotoxicity potential revealed by fraction F4, the EMSA performed in the present study for assessment of AP1 DNA- binding activity revealed a stronger inhibition of AP1 activity by crude extracts as compared to more cytotoxic fraction F4. Similarly, the inhibition of viral transcription of HPV18 was lesser in cells treated with fraction F4 which was considered to have higher concentration of active principle. These results suggest that fraction F4 of B. pinnata leaf extracts might possess two distinct activities which apart from inhibiting activity of transcription factors like AP1 that are responsible for expression of viral oncoproteins (E6 \& E7) through binding to URR resulting in oncogenic cell division, can independently prevent cell growth of cancer cells by alternate mechanism(s). This assumption get strength from the finding that cells treated with fraction F4, unlike crude extract, had strongly reduced JunD levels along with reduced c-Jun and c-Fos. Such changes in components of AP1 complex may have varied implication in cellular context and the same could have been translated in higher cytotoxic potential of fraction F4 despite affecting HPV18 transcription at lesser level.

Results of present investigation indicated that cells treated with $B$. pinnata extracts undergo phytochemicalspecific programmed cell death/apoptosis and did not induce non-specific necrotic death. A time-dependent appearance of pro-apototic Bax and loss of anti-apoptotic Bcl-2 along with caspase-3 activation and PARP-1 cleavage over $24 \mathrm{~h}$ time period strongly supported this assumption. Like, majority of cytotoxic phytochemicals, B. pinnata induced apoptotic cell death via intrinsic pathway through loss of mitochondrial membrane potential that are known to be accompanied by Bax expression and loss of Bcl-2 [28,34-36].

In an effort to characterize the active principle through NMR and HPTLC our study revealed that one of the cardiac glycoside that converge in fraction F4 could be bryophyllin-A. However, the study showed presence of high levels of alkaloid that also converge to fraction F4. A number of bioactive molecules including flavanoids, glycosides, steroids, bufadienolides and organic acids have been identified in several studies $[10,11,37]$. Interestingly, one of the flavanoid glycoside, quercetin analog Quercitrin (quercetin 3- O-alpha- Lrhamnopyranoside) and skapinnatoside, has been shown in several studies to possess anti-leishmanial and antiinflammatory activities $[8,15,38]$. In addition, Bufadienolides, bryophyllin-A, - B, - C and bersaldegenin-1, 3, 5orthoacetate were isolated from the plant of Taiwan origin and was shown to possess hepato-protective activity and cytotoxicity [31,39-41,31]. Apart from this bryophyllol, bryophollone, bryophollenone, bryophynol, 2(9-decenyl) phenenthrene (I), 2(undecenyl) phenenthrene (II), $18 \alpha$-oleanane, $\psi$-taraxasterol, $\alpha$-and $\beta$-amyrins and their acetates, 24-epiclerosterol [24(R) stigmasta-5, 25-dien$3 \beta$-ol], 24(R) $5 \alpha$-stigmasta-7, 25-dien-3 $\beta$-ol, $5 \alpha$-stigmast-24-en-3 $\beta$-ol and 25-methyl- $5 \alpha$-ergost-24(28)-en$3 \beta$-ol were isolated from the plant leaves and other aerial parts $[42,43]$. Therefore, it is difficult to conclude from the present study that anti-HPV/anticancer activity observed in crude leaf extract or fraction F4 is displayed specifically by any single chemical entity. Though in unrelated experimental model of EBV-early antigen activation in Raji cells, among 5 different bufadienolides isolated from kalanchoe pinnata, showed anti-tumor promoting activity [40] and among them bryophyllin A was found to possess strongest activity. In another study, three new compounds, kalanchosides A-C, as well as five known compounds, were isolated from the aerial parts of Kalanchoe gracilis, where all eight isolated compounds showed significant cytotoxic activity against a panel of human tumor cell lines. However, only one of the known compound bryophyllin B inhibited HIV replication in H9 lymphocyte cells [44].

\section{Conclusion}

Our study indicates for the first time that B. pinnata can act as an anti-HPV molecule and apoptosis- inducing property. It therefore provides an important lead for development of anti-cancer therapeutics for management of cervical cancer. Further analysis and purification of the $B$. pinnata leaf extract and in vivo studies may help in discovering the full potential of $B$. pinnata as a source of an effective antiviral/anti-cancer drug.

\section{Acknowledgements}

This work was supported by the funds from Indian Council of Medical Research (ICMR), and Department of Biotechnology, Government of India (to A.C.B and B.C.D). The authors thank Dr. Sayeed, Lecturer, Dept of Pharmacognosy and Phytochemistry, Jamia Hamdard, New Delhi, for immense help in biochemical and HPTLC analysis. 


\section{Author details}

'Division of Molecular Oncology, Institute of Cytology and Preventive Oncology (ICMR), I-7, Sector-39, Noida 201301, INDIA. '2Department of Inorganic and Physical Chemistry, Indian Institute of Science, Bangalore 560 012, INDIA. ${ }^{3}$ Dr. B.R Ambedkar Centre for Biomedical Research, University of Delhi (North Campus), Delhi 110007, INDIA.

\section{Authors' contributions}

S Mahata and S Maru contributed equally to this work. S Mahata and S Maru designed methods and experiments, carried out the laboratory experiments, analyzed the data, interpreted the results and wrote the paper. SS and AP co-worked on western blotting experiments and their interpretation. GM designed and worked on NMR experiments. ACB and BCD defined the research theme, discussed analysis, interpretation, and presentation. All contributing authors seen and approved the manuscript.

\section{Competing interests}

The authors declare that they have no competing interests.

Received: 14 November 2011 Accepted: 10 March 2012 Published: 10 March 2012

\section{References}

1. Tan G, Gyllenhaal C, Soejarto DD: Biodiversity as a source of anticancer drugs. Curr Drug Targets 2006, 7(3):265-277.

2. Akinpelu DA: Antimicrobial activity of Bryophyllum pinnatum leaves. Fitoterapia 2000, 71(2):193-194.

3. Misra SaD SN: Antifungal activity of leaf extract of some higher plants. Acta Botanica Indica 1979, 7:147-150.

4. Pal S, Nag Chaudhuri AK: Studies on the anti-ulcer activity of a Bryophyllum pinnatum leaf extract in experimental animals. J Ethnopharmacol 1991, 33(1-2):97-102.

5. Pal S, Nag Chaudhuri AK: Preliminary studies on the anti-inflammatory and analgesic activities of bryophyllum pinnatum (Lam.). Med Sci Res 1989, 17:561-562.

6. Pal S, Nag Chaudhuri AK: Further studies on the anti-inflammatory profile of the methanolic fraction of the fresh leaf extract of bryophyllum pinnatum. Fitoterapia 1992, 63:451-459.

7. Ojewole JAO: Antihypertensive properties of bryophyllum pinnatum (Clam; oken) leaf extracts. Am J Hypert 2002, 15(4):A34-A39.

8. Ojewole JA: Antinociceptive, anti-inflammatory and antidiabetic effects of Bryophyllum pinnatum (Crassulaceae) leaf aqueous extract. J Ethnopharmacol 2005, 99(1):13-19.

9. Umbuzeiro-Valent G, Roubicek DA, Haebisch EM: Mutagenic and antimutagenic evaluation of the juice of the leaves of Bryophyllum calycinum (Kalanchoe pinnata), a plant with antihistamine activity. Environ Mol Mutagen 1999, 33(4):325-327.

10. Gaind KN, Gupta RL: Flavonoid glycosides from Kalanchoe pinnata. Planta Med 1971, 20(4):368-373

11. Marriage PB, Wilson DG: Analysis of the organic acids of Bryophyllum calycinum. Can J Biochem 1971, 49(3):282-296.

12. Muzitano MF, Falcao CA, Cruz EA, Bergonzi MC, Bilia AR, Vincieri FF, RossiBergmann B, Costa SS: Oral metabolism and efficacy of Kalanchoe pinnata flavonoids in a murine model of cutaneous leishmaniasis. Planta Med 2009, 75(4):307-311.

13. Muzitano MF, Tinoco LW, Guette C, Kaiser CR, Rossi-Bergmann B, Costa SS: The antileishmanial activity assessment of unusual flavonoids from Kalanchoe pinnata. Phytochemistry 2006, 67(18):2071-2077.

14. Torres-Santos EC, Da Silva SA, Costa SS, Santos AP, Almeida AP, RossiBergmann B: Toxicological analysis and effectiveness of oral Kalanchoe pinnata on a human case of cutaneous leishmaniasis. Phytother Res 2003, 17(7):801-803.

15. Muzitano MF, Cruz EA, de Almeida AP, Da Silva SA, Kaiser CR, Guette C, Rossi-Bergmann B, Costa SS: Quercitrin: an antileishmanial flavonoid glycoside from Kalanchoe pinnata. Planta Med 2006, 72(1):81-83.

16. Da-Silva SA, Costa SS, Rossi-Bergmann B: The anti-leishmanial effect of Kalanchoe is mediated by nitric oxide intermediates. Parasitology 1999, 118(Pt 6):575-582.

17. Cao H, Xia J, Xu D, Lu B, Chen G: The separation and identification of the flavonoids from the leaves of Bryophyllum pinnatum. Zhong Yao Cai 2005, 28(11):988-990.
18. Parkin DM: The global health burden of infection-associated cancers in the year 2002. Int J Cancer 2006, 118(12):3030-3044.

19. Durst M, Gissmann L, Ikenberg $H$, zur Hausen $H$ : A papillomavirus DNA from a cervical carcinoma and its prevalence in cancer biopsy samples from different geographic regions. Proc Natl Acad Sci USA 1983, 80(12):3812-3815.

20. Boshart M, Gissmann L, Ikenberg H, Kleinheinz A, Scheurlen W, zur Hausen $\mathrm{H}$ : A new type of papillomavirus DNA, its presence in genital cancer biopsies and in cell lines derived from cervical cancer. EMBO J 1984, 3(5):1151-1157.

21. zur Hausen $\mathrm{H}$ : Papillomaviruses causing cancer: evasion from host-cell control in early events in carcinogenesis. J Nat/ Cancer Inst 2000, 92(9):690-698.

22. Chen HC, Schiffman M, Lin CY, Pan MH, You SL, Chuang LC, Hsieh CY Liaw KL, Hsing AW, Chen CJ: Persistence of type-specific human papillomavirus infection and increased long-term risk of cervical cancer. J Natl Cancer Inst 2011, 103(18):1387-1396.

23. Zur Hausen $\mathrm{H}$ : Papillomaviruses and cancer: from basic studies to clinical application. Nat Rev Cancer 2002, 2(5):342-350.

24. Satoru Kyo DJK, Masaki Inoue, Taro Kanaya, Laimins ALaimonis: Expression of AP1 during cellular differentiation determines human papillomavirus E6/E7 expression in stratified epithelial cells. J Gen Virol 1997, 78:401-411.

25. Butz K, Hoppe-Seyler F: Transcriptional control of human papillomavirus (HPV) oncogene expression: composition of the HPV type 18 upstream regulatory region. J Virol 1993, 67(11):6476-6486.

26. Prusty BK, Das BC: Constitutive activation of transcription factor AP-1 in cervical cancer and suppression of human papillomavirus (HPV) transcription and AP-1 activity in HeLa cells by curcumin. Int $J$ Cancer 2005, 113(6):951-960.

27. Bharti AC, Shukla S, Mahata S, Hedau S, Das BC: Anti-human papillomavirus therapeutics: facts \& future. Indian J Med Res 2009, 130(3):296-310.

28. Mahata S, Bharti AC, Shukla S, Tyagi A, Husain SA, Das BC: Berberine modulates AP-1 activity to suppress HPV transcription and downstream signaling to induce growth arrest and apoptosis in cervical cancer cells. Mol Cancer 2011, 10:39.

29. Shukla S, Bharti AC, Hussain S, Mahata S, Hedau S, Kailash U, Kashyap V, Bhambhani S, Roy M, Batra S, et al: Elimination of high-risk human papillomavirus type HPV16 infection by 'Praneem' polyherbal tablet in women with early cervical intraepithelial lesions. J Cancer Res Clin Oncol 2009, 135(12):1701-1709.

30. Zhengyin Yan GC: Evaluation of cytochrome P450 inhibition in human liver microsomes. In Optimization in drug discovery: in vitro methods. Edited by: Zhengyin Yan GWC. Totowa, NJ: Humana press; 2004:231-244.

31. Yamagishi T, Haruna M, Yan XZ, Chang JJ, Lee KH: Antitumor agents, 110. Bryophyllin B, a novel potent cytotoxic bufadienolide from Bryophyllum pinnatum. J Nat Prod 1989, 52(5):1071-1079.

32. Emmanuel E, Obaseiki-Ebor KO, Telikepalli Hannumaiah, Mitscher Lester A, Delbert M: Shankel: Antimutagenic activity of extracts of leaves of four common edible vegetable plants in Nigeria (West Africa). Mutat Res Lett 1993, 302(2):109-117

33. Eferl R, Wagner EF: AP-1: a double-edged sword in tumorigenesis. Nat Rev Cancer 2003, 3(11):859-868.

34. el SA Arafa, Zhu Q, Shah ZI, Wani G, Barakat BM, Racoma I, El-Mahdy MA, Wani AA: Thymoquinone up-regulates PTEN expression and induces apoptosis in doxorubicin-resistant human breast cancer cells. Mutat Res 2011, 706(1-2):28-35.

35. Bharti AC, Donato N, Singh S, Aggarwal BB: Curcumin (diferuloylmethane) down-regulates the constitutive activation of nuclear factor-kappa $B$ and IkappaBalpha kinase in human multiple myeloma cells, leading to suppression of proliferation and induction of apoptosis. Blood 2003, 101(3):1053-1062.

36. Halder B, Bhattacharya U, Mukhopadhyay S, Giri AK: Molecular mechanism of black tea polyphenols induced apoptosis in human skin cancer cells: involvement of Bax translocation and mitochondria mediated death cascade. Carcinogenesis 2008, 29(1):129-138.

37. El Abdellaoui S, Destandau E, Toribio A, Elfakir C, Lafosse M, Renimel I, Andre P, Cancellieri P, Landemarre L: Bioactive molecules in Kalanchoe pinnata leaves: extraction, purification, and identification. Anal Bioanal Chem 2010, 398(3):1329-1338. 
38. Anjoo Kamboj aAKS: Bryophyllum pinnatum (Lam.) Kurz.: Phytochemical and pharmacological profile: A review. Pharmacognosy Rev 2009, 3(6):364-374.

39. Yamagishi T, Yan XZ, Wu RY, McPhail DR, McPhail AT, Lee KH: Structure and stereochemistry of bryophyllin-A, a novel potent cytotoxic bufadienolide orthoacetate from Bryophyllum pinnatum. Chem Pharm Bull(Tokyo) 1988, 36(4):1615-1617.

40. Supratman U, Fujita T, Akiyama K, Hayashi H: New insecticidal bufadienolide, bryophyllin C, from Kalanchoe pinnata. Biosci Biotechnol Biochem 2000, 64(6):1310-1312.

41. Supratman U, Fujita T, Akiyama K, Hayashi H, Murakami A, Sakai H, Koshimizu K, Ohigashi H: Anti-tumor promoting activity of bufadienolides from Kalanchoe pinnata and K. daigremontiana $\mathrm{x}$ tubiflora. Biosci Biotechnol Biochem 2001, 65(4):947-949.

42. Toshihiro Akihisa WCMCK, Tamura Toshitake, Matsumoto Taro: Sterols ofKalanchoe pinnata: First report of the isolation of both C-24 epimers of 24-alkyl- $\Delta 25$-sterols from a higher plant. Lipids 1991, 26(8):660-665.

43. Salimuzzaman Siddiqui SF, Siddiqui Bina S, Naheed Sultana: Triterpenoids and phenanthrenes from leaves of Bryophyllum pinnatum. Phytochemistry 1989, 28(9):2433-2438.

44. Wu PL, Hsu YL, Wu TS, Bastow KF, Lee KH: Kalanchosides A-C, new cytotoxic bufadienolides from the aerial parts of Kalanchoe gracilis. Org Lett 2006, 8(23):5207-5210.

\section{Pre-publication history}

The pre-publication history for this paper can be accessed here: http://www.biomedcentral.com/1472-6882/12/15/prepub

doi:10.1186/1472-6882-12-15

Cite this article as: Mahata et al.: Anticancer property of Bryophyllum pinnata (Lam.) Oken. leaf on human cervical cancer cells. BMC Complementary and Alternative Medicine 2012 12:15.

\section{Submit your next manuscript to BioMed Central and take full advantage of:}

- Convenient online submission

- Thorough peer review

- No space constraints or color figure charges

- Immediate publication on acceptance

- Inclusion in PubMed, CAS, Scopus and Google Scholar

- Research which is freely available for redistribution

Submit your manuscript at www.biomedcentral.com/submit 